\title{
Upper gastrointestinal pathology in familial adenomatous polyposis: results from a prospective study of 102 patients
}

\author{
P Domizio, I C Talbot, A D Spigelman, C B Williams, R K S Phillips
}

\begin{abstract}
Multiple gastric and duodenal biopsy specimens from 102 asymptomatic patients with familial adenomatous polyposis, taken during a prospective endoscopic screening programme were examined. One hundred patients had microscopic gastroduodenal pathology, often in the absence of macroscopic lesions. Adenomas were found in 94 patients in the duodenum, in the second and third parts. Hyperplasia of villous and crypt epithelium was also seen, sometimes in the absence of adenomas: this may be a precursor of neoplastic change. In the stomach fundic gland polyps were the commonest abnormality, seen microscopically in 44 patients. Chronic antral gastritis was common in patients without fundic polyps. Gastric adenomas were present in six patients, all of whom also had duodenal adenomas.

If duodenal adenomas in familial adenomatous polyposis have a similar malignant potential to those in the colorectum sequential endoscopy and biopsy are necessary to detect cancer in these patients.
\end{abstract}

Familial adenomatous polyposis (FAP) is an inherited autosomal dominant condition, with the gene locus on chromosome $5,{ }^{1}$ in which multiple adenomas with malignant potential are found throughout the colorectum. The previous names for this disease (familial polyposis coli, familial adenomatosis coli) neglected the fact that a high proportion of patients have accompanying neoplastic and non-neoplastic polyps in the upper gastrointestinal tract. This observation was first made by Hauser in $1895^{2}$; he described multiple polyps of the gastric antrum and duodenum in a patient with polyposis at necropsy. Similar cases were reported sporadically thereafter until the early 1970s when the Japanese began to report a high incidence of accompanying gastroduodenal lesions in FAP. ${ }^{3-6}$ Workers in the West subsequently published similar findings, ${ }^{7-13}$ although until recently, the proportion of affected patients has been lower than that reported from Japan. $^{7-11}$

In the duodenum adenomas are undoubtedly the commonest lesion, the prevalence varying from $24 \%{ }^{11}$ to $100 \%{ }^{4}$ of cases. Periampullary carcinoma is the most common extra-colonic site of malignancy in FAP, occurring in $2.9 \%$ of patients in a recent large series. ${ }^{14}$ In fact, in patients with FAP treated routinely by colectomy at St Mark's hospital over the past 40 years, periampullary carcinoma was the commonest cause of death from neoplasia, accounting for twice as many deaths as colorectal carcinoma. ${ }^{15}$

In the stomach the histological type of polyps varies according to the site. Fundic gland polyps, first reported by Utsonomyia et al,,$^{15}$ occur in the gastric body and fundus of a high proportion of patients with FAP..$^{910} 1617$ Originally thought to be unique to $\mathrm{FAP}^{3}$ these polyps are now being found increasingly in other patients without FAP. ${ }^{18-21}$ The histogenesis of these lesions has been in doubt and they have variously been described as hyperplastic, ${ }^{911} 12$ regenerative, ${ }^{17}$ and, more commonly, hamartomatous. ${ }^{1021}$ Adenomas are the most common antral lesion, but these occur less frequently than duodenal adenomas. ${ }^{9101322}$ Apart from sporadic case reports, ${ }^{4324}$ in most large series gastric carcinoma has not shown an increased incidence in FAP compared with that in the general population. ${ }^{14}$

Despite a large number of reports on this subject in recent years appreciation of these gastroduodenal lesions has been hampered by inadequate descriptions of the pathology and by small numbers of patients in many series. In this paper we report the pathological features in patients with FAP from a prospective upper gastrointestinal screening programme carried out at St Mark's Hospital.

\section{Methods}

The subjects comprised 102 patients with confirmed FAP from 69 families on the St Mark's polyposis register. There were 69 men and 53 women with a mean age of 41 years (range $=14-66$ years). None of the patients had symptoms referable to the upper gastrointestinal tract. All patients underwent endoscopy by the same endoscopist (CBW) according to a set protocol. A forward viewing endoscope (GIFXQ10) was used for the first six patients and a side viewing videoendoscope (Olympus JFV10) for the remainder. The site, number, and size of polyps seen were noted and a map of the periampullary region drawn for comparison at follow up endoscopies. Biopsy specimens were taken of representative gastric and duodenal polyps with random antral and duodenal biopsy specimens when no lesions were seen. An 
Table 1 Numbers of gastric and duodenal polyps found at endoscopy in 102 patients with FAP

\begin{tabular}{lllll}
\hline \multirow{5}{*}{ Site } & \multicolumn{5}{l}{ Number of polyps } \\
\cline { 2 - 5 } & 0 & $<5$ & $5-20$ & $>20$ \\
\hline Duodenum & 13 & 12 & 40 & 37 \\
Stomach & 46 & 4 & 20 & 32 \\
\hline
\end{tabular}

average of three gastric biopsy specimens was taken from 81 of the 102 patients while all 102 patients had an average of five duodenal biopsy specimens taken. In total, 735 gastric and duodenal biopsy specimens were examined histologically.

All specimens were fixed in $10 \%$ unbuffered formol-saline and processed to paraffin wax. Sections $(3 \mu \mathrm{m})$ were cut at multiple levels and stained with haematoxylin and eosin and a modified Giemsa technique. A combined periodic acid Schiff/alcian blue stain was carried out on selected biopsy specimens. All sections were examined by two of the authors (PD and ICT).

\section{Results}

STOMACH

Fifty six patients had endoscopically visible gastric polyps (table 1). In most cases these were small (mean $=4.7 \mathrm{~mm}$ ), multiple, and confined to the fundus and body (fig 1). A small number of patients had few polyps which tended to be larger (mean $=6.4 \mathrm{~mm}$ ) and antral.

Table 2 summarises the microscopic gastric pathology, excluding the adenomas. Of the 54 patients with macroscopic fundic polyps, 44 showed histological features consistent with this diagnosis, although six had normal histology. The surface and foveal epithelium

Figure 1 Overall representation of sites affected by upper gastrointestinal polyposis. For the 102 patients in this study, $\bigcirc$ represents one patient with fundic gland polyp $(s), 0$ represents one patient with adenoma $(s)$. Figure reproduced by permission of the Lancet.

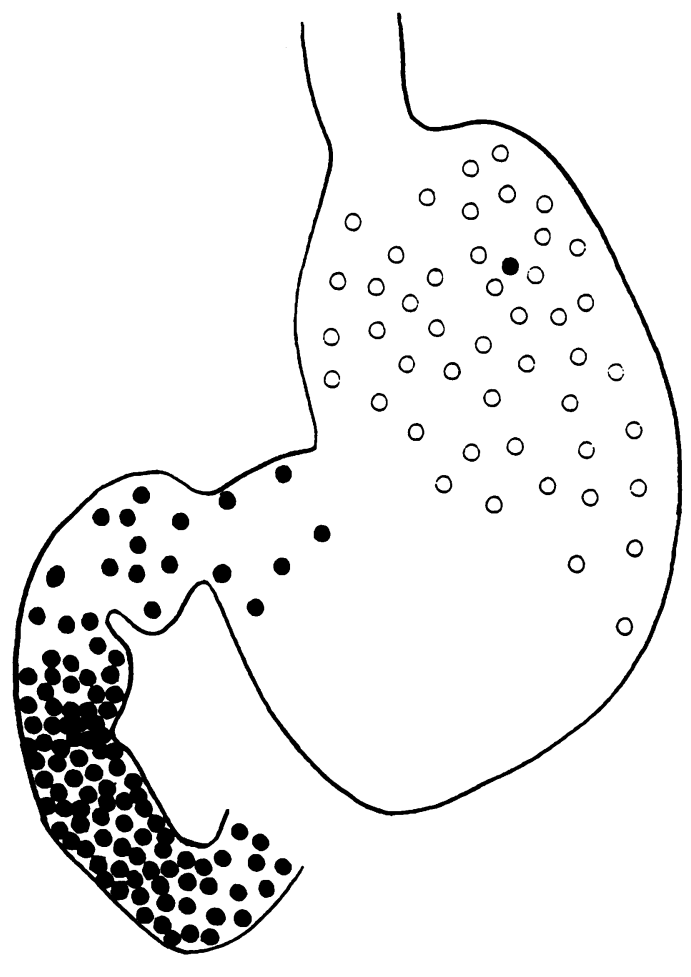

Table 2 Gastric pathology, excluding adenomas, in 102 patients with $F A P$

\begin{tabular}{|c|c|c|c|}
\hline \multirow[b]{2}{*}{ Macroscopic appearances } & \multicolumn{3}{|c|}{ Histology } \\
\hline & Normal & $\begin{array}{l}\text { Features of } \\
\text { fundic gland } \\
\text { polyps }\end{array}$ & $\begin{array}{l}\text { Gastritis } \\
\text { only }\end{array}$ \\
\hline \multirow{2}{*}{$\begin{array}{l}\text { Fundic polyps present } \\
\text { (54 patients) } \\
\text { Fundic polyps absent } \\
\text { (48 patients) }\end{array}$} & 6 & $44^{\star}$ & 1 \\
\hline & 6 & $8 \dagger$ & 15 \\
\hline
\end{tabular}

$\star$ Six patients also had gastritis.

†One patient also had gastritis.

overlying most of the polyps was hyperplastic, although occasionally small groups of specialised glands did extend almost up to the surface (fig 2), implying some loss of foveolae. Dilatation of specialised glands in the superficial half of the mucosa was seen in most cases, but the degree varied from minimal (fig 2) to frankly cystic (fig 3 ). The cyst lining was sometimes attenuated and comprised a mixture of chief cells, parietal cells, and mucussecreting cells (fig 3). About $20 \%$ of patients with macroscopic fundic polyps showed surface and foveal hyperplasia without glandular dilatation; these patients were included in the group showing positive histological features. Inflammation in the lamina propria was not seen in any of the fundic gland polyps, but coincident antral gastritis was present in six patients.

Fundic polyps were absent in 48 patients, 29 of whom had random antral biopsy specimens taken (table 2). Chronic antral gastritis was the commonest single abnormality in this group, but interestingly eight patients showed features similar to those seen in fundic gland polyps-surface and foveal hyperplasia with glandular dilatation-even though the mucosa was macroscopically normal and the biopsy specimen was antral.

Gastric adenomas were seen in six patients (table 3), all but one of them in the antrum. The one patient with an adenoma in the body also had at least one antral adenoma. Five of the six patients had macroscopic antral polyps while one adenoma was discovered at random antral biopsy. Most adenomas were tubular (fig 4), and all but one showed mild dysplasia. One patient showed adenomatous dysplasia in what seemed to be an underlying fundic gland polyp (fig 5).

Asymptomatic chronic gastritis was seen in 23 patients, predominantly in the antrum. Active chronic superficial gastritis was the most common histological type, while chronic atrophic gastritis was much less so. Helicobacter pylori were seen lining the mucosal surface and within gland lumina in 17 patients.

\section{DUODENUM}

Eighty nine patients had endoscopically visible duodenal polyps (table 1 ) which tended to be more numerous and larger (mean $=9.4$ $\mathrm{mm}$ ) than those seen in the stomach. Only 13 patients had no duodenal polyps.

On subsequent histological examination, all 


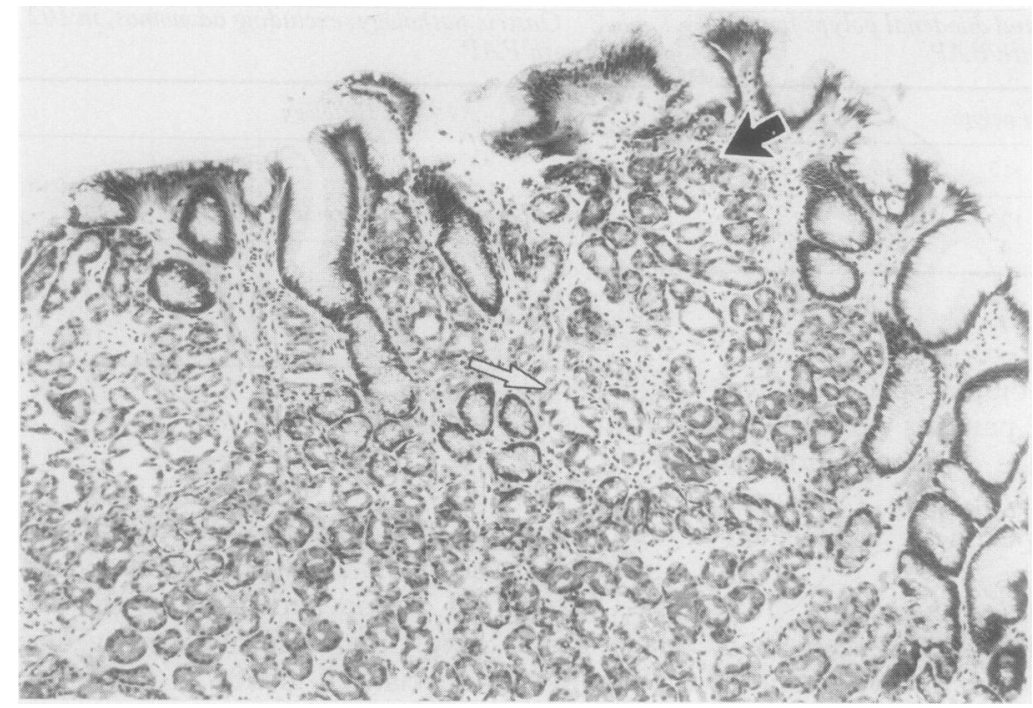

Figure 2 Fundic gland polyp showing minimal gland dilatation (long arrow). A group of specialised glands extends almost to the epithelial surface (short arrow) (haematoxylin and eosin).

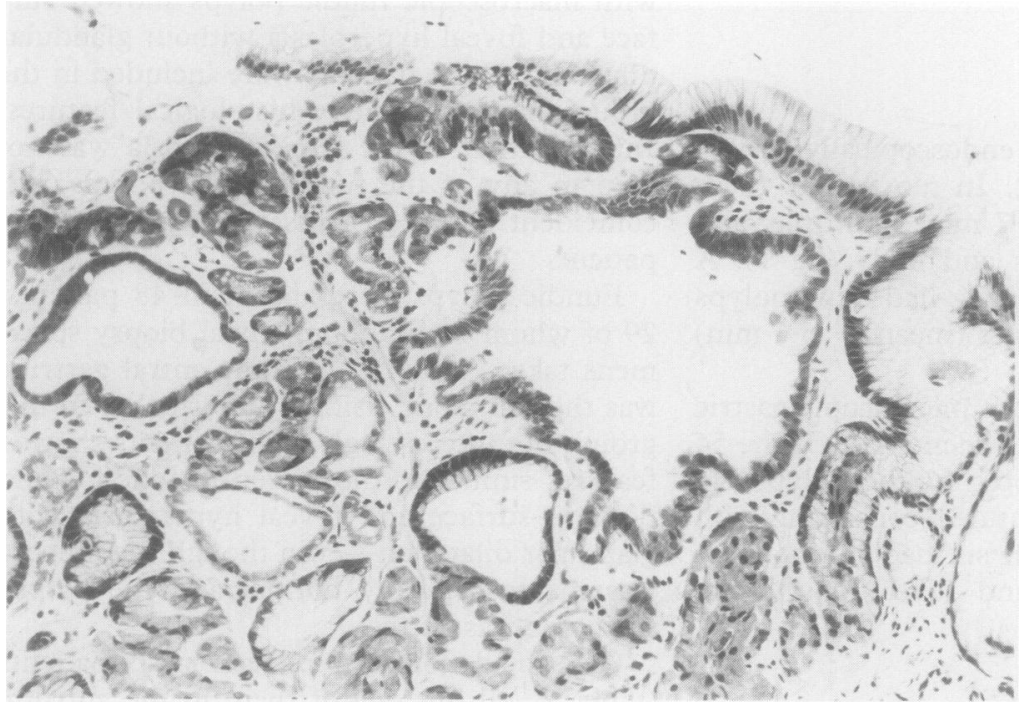

Figure 3 Fundic gland polyp showing a cystically dilated gland lined by chief cells, parietal cells, and mucus secreting cells (haematoxylin and eosin).

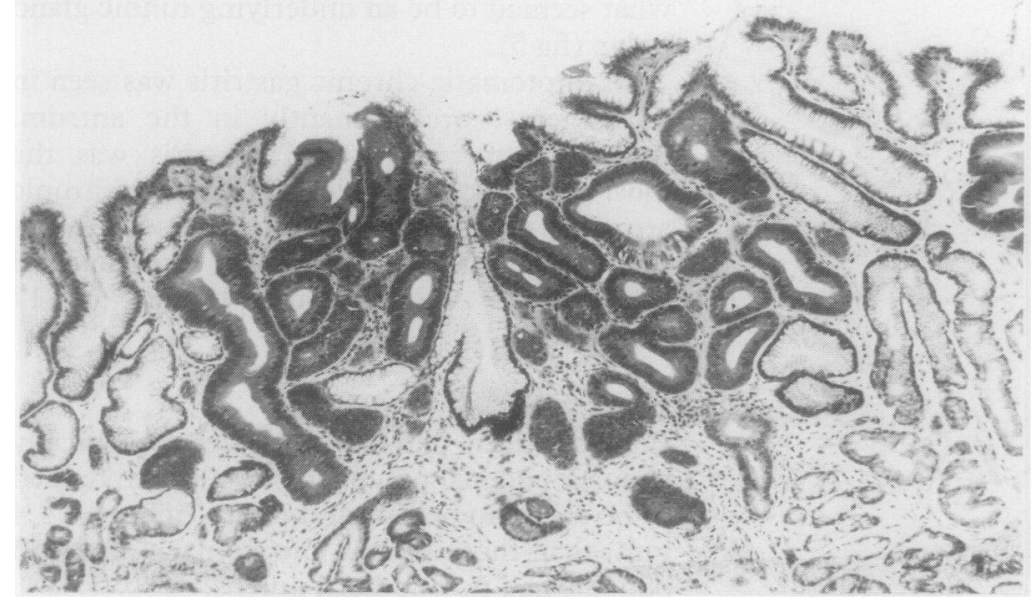

Figure 4 Mildly dysplastic tubular adenoma in the antrum (haematoxylin and eosin).
Table 3 Location and histological type of seven gastric adenomas in six patients with FAP

\begin{tabular}{llll}
\hline & \multicolumn{2}{l}{ Adenoma type } \\
\cline { 2 - 4 } Site & Tubular & Tubulovillous & Villous \\
\hline Antrum & 4 & 2 & 0 \\
Body & 0 & 0 & 1 \\
\hline
\end{tabular}

Table 4 Duodenal pathology in 102 patients with FAP

\begin{tabular}{llll}
\hline & \multicolumn{1}{c}{ Histology } & \\
\cline { 2 - 4 } $\begin{array}{l}\text { Macroscopic } \\
\text { appearance }\end{array}$ & Normal & $\begin{array}{l}\text { Villous/crypt } \\
\text { hyperplasia } \\
\text { alone }\end{array}$ & Adenoma \\
\hline $\begin{array}{c}\text { Polyps present } \\
\text { (89 patients) }\end{array}$ & 0 & 2 & 87 \\
$\begin{array}{l}\text { Polyps absent } \\
\text { (13 patients) }\end{array}$ & 2 & 4 & 7 \\
Total & 2 & 6 & 94 \\
\hline
\end{tabular}

Table 5 Histological type and degree of dysplasia of duodenal adenomas in 94 patients with FAP

\begin{tabular}{llll}
\hline & \multicolumn{2}{l}{ Dysplasia } & \\
\cline { 2 - 4 } Adenoma type & Mild & Moderate & Severe \\
\hline Tubular & 60 & 8 & 0 \\
Tubulovillous & 15 & 4 & 0 \\
Villous & 3 & 4 & 0 \\
\hline
\end{tabular}

but two of the patients with macroscopic polyps had microscopic adenomas (table 4). The remaining two showed hyperplasia of the epithelium lining parts of the villi and crypts (fig 6), characterised by enterocyte crowding, nuclear enlargement and hyperchromasia, increased mitoses and loss of goblet cells. Although the features were qualitatively similar to those seen in adenomas, the severity of the changes fell short of our threshold for dysplasia. This abnormality, when present, was usually seen consistently in multiple biopsy specimens from the same patient, and in about $30 \%$ of patients adenomas and hyperplasia were seen in the same set of specimens. An increased number of Paneth cells were seen in some of the hyperplastic crypts of three patients. This was difficult to quantitate and was not directly related to other features of hyperplasia or dysplasia.

Of the 13 patients without duodenal polyps, seven had microscopic adenomas (table 3), making a total of $94(92 \%)$ patients with adenomas. A further four patients had villous and crypt epithelial hyperplasia, so that only two patients of the entire series had normal duodenal histology.

Two thirds of the duodenal adenomas were mildly dysplastic and tubular (table 5). Villous adenomas were much less common and none of the adenomas showed more than moderate dysplasia. Invasive carcinomas were not detected in any of the patients.

The distribution of adenomas is shown diagrammatically in fig 1 . Most adenomas were located in the second and third parts of the duodenum with periampullary clustering. 


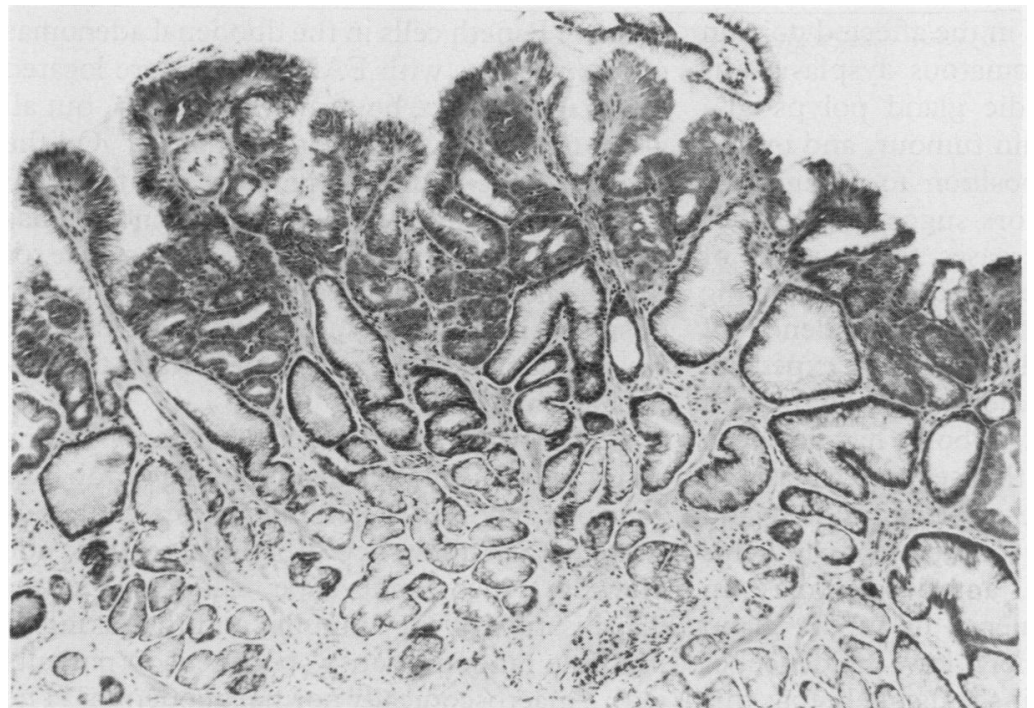

Figure 5 Gastric biopsy specimen showing the features of a fundic gland polyp with mild dysplasia of the surface epithelium (haematoxylin and eosin).

\author{
Figure 6 Duodenal \\ biopsy specimen showing \\ hyperplasia of the \\ epithelium lining parts of \\ the villi (arrows). This is \\ characterised by enterocyte \\ crowding, loss of goblet \\ cells, and nuclear \\ enlargement and \\ hyperchromasia. The \\ epithelium lining the villus \\ on the left appears normal \\ (haematoxylin and eosin).
}

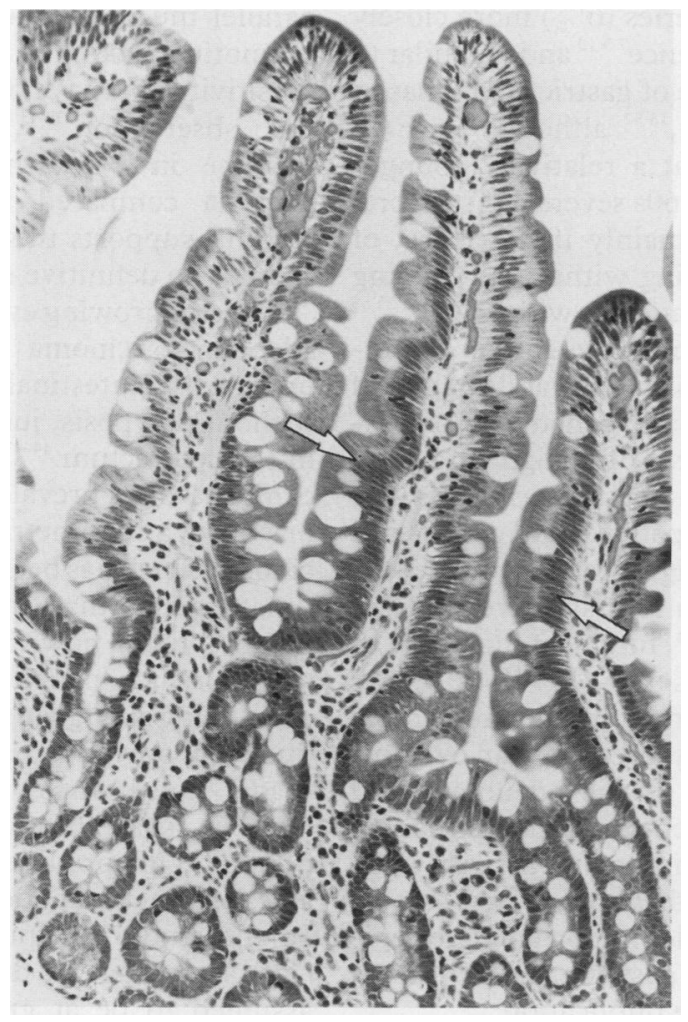

No patients had adenomas confined to the first part of the duodenum or the gastric antrum; when they were present here, they were always present more distally.

\section{Discussion}

Fundic gland polyps are the commonest gastric lesion in FAP, with a reported prevalence of $27-73^{\circ} \circ .{ }^{3-5,7-12}$ In other patients fundic gland polyps are more common than was previously thought, occurring in up to $1.4 \%$ of gastroscopic examinations ${ }^{21}$ and constituting $17 \%$ of gastric polyps in a recent series. ${ }^{18}$ Previous descriptions of the histology of fundic gland polyps have been inconsistent. Most authors agree that there is dilatation of the specialised glands in the superficial half of the mucosa, ${ }^{317212526}$ but opinion has varied as to whether the overlying surface and foveal epithelium is hyperplastic ${ }^{39111824}$ or atrophic. ${ }^{172126}$ In this series hyperplasia was almost invariably present, although, as previously described, features suggestive of focal foveal atrophy were occasionally seen.

Fundic gland polyps have been considered by some authors to be of hyperplastic or regenerative aetiology. ${ }^{891117}$ In contrast to hyperplastic polyps, however, fundic gland polyps tend to be smaller and located in the fundus and body rather than throughout the stomach. ${ }^{18}$ Hyperplasia of surface and foveal epithelium with elongated pits is seen in both types of polyp, ${ }^{18}$ but in hyperplastic polyps there is cystic dilatation of foveolae and pyloric type glands, ${ }^{27}$ while in fundic gland polyps many of the dilated glands are of specialised, or body type. ${ }^{27}$ In addition, the stromal inflammation and smooth muscle arborisation often seen in hyperplastic polyps are absent in fundic gland polyps. ${ }^{18} \mathrm{~A}$ small number of patients in this series showed antral epithelial hyperplasia and mild foveolar dilatation, features in keeping with hyperplastic polyps. True hyperplastic polyps, however, are rare in $\mathrm{FAP},{ }^{10}$ and in the absence of macroscopic polyps it seems more likely that the changes described were secondary to bile reflux, a phenomenon which has been shown to occur in some patients with FAP. ${ }^{28}$

The most popular theory to date on the aetiology of fundic gland polyps is that they represent cystic hamartomas. ${ }^{310212930}$ Fundic gland polyps, however, are formed almost entirely of epithelial elements and are thus unlike other types of hamartoma in the gastrointestinal tract which are composed predominantly of proliferated connective tissue. Studies on the natural history of fundic gland polyposis (of both syndromic and non-syndromic types) have shown that these polyps can diminish in size and number, or even disappear altogether, ${ }^{91619}$ particularly after colectomy in patients with FAP. ${ }^{319}$ Such an observation has not been made with other types of gastrointestinal hamartoma. The high mean age of patients with non-syndromic fundic gland polyposis $(50-60 \text { years })^{16171926}$ also argues against a hamartomatous origin.

A functional or secretory aetiology for fundic gland polyps has recently been proposed by Eidt and Stolte. ${ }^{16}$ These authors suggest that the gastrointestinal adenomas in patients with FAP may produce a substance which circulates systemically and leads to local overstimulation of fundic and body glands, resulting in cystic dilatation. The observation that fundic gland polyps may increase in size following pentagastrin stimulation ${ }^{31}$ and the observed decrease in the number of fundic gland polyps after colectomy are quoted as evidence in favour of this hypothesis. Despite the theoretical attractiveness of this theory, however, no such circulating substance has ever been identified.

Goodman et al reported two patients with FAP and fundic gland polyposis who devel- 
oped gastric carcinomas in the affected portion of the stomach. ${ }^{24}$ Adenomatous dysplasia was identified in some fundic gland polyps discontinuous with the main tumour, and on the basis of this, a predisposition to malignancy was inferred. The authors suggested that the presence of polyps increases the number of gastric epithelial cells exposed to carcinogenic agents and that an increased incidence of malignant change would therefore be expected. The association of fundic gland polyps with dysplasia or carcinoma, or both, has not been reported elsewhere. In this series dysplasia in what seemed to be a pre-existing fundic gland polyp was seen in only one patient, and this patient also had several antral adenomas. In view of the high prevalence of fundic gland polyps and the extremely low incidence of dysplasia within them, it seems likely that this observed association is fortuitous.

Gastric adenomas have been reported by some Japanese authors to occur in up to $60 \%$ of patients with FAP. ${ }^{3422}$ The prevalence of gastric adenomas in this series $(6 \%)$ more closely reflects Western experience ${ }^{7910}$ and is similar to the reported prevalence of gastric adenomas in the general population, ${ }^{182}$ although in FAP they tend to develop at a relatively younger age. ${ }^{22}$ Since the early 1960 s several case reports have been published, mainly in Japanese, of gastric carcinomas arising within pre-existing antral adenomas in patients with FAP. ${ }^{4333}$ Watanabe et al found multiple gastric carcinomas in three of their 26 patients and suggested that patients with FAP are genetically predisposed to the development of malignant gastric tumours. ${ }^{4}$ The same authors described gastric microcarcinoids in two patients and considered this association to be significant. More recently, Jagelman et al, in a retrospective study of 1255 patients with FAP, found an incidence of gastric carcinoma of less than $1 \% .{ }^{14}$ The higher incidence of gastric carcinoma in the general population in Japan may have led to an overemphasis of the risk of gastric adenomas and cancer in Japanese patients with polyposis.

The presence of asymptomatic gastritis in 23 patients (associated with $H$ pylori in 17) is an observation of possible importance to epidemiological studies of gastritis, and will form the subject of a separate publication.

Epithelial hyperplasia in the duodenum is an abnormality which has not previously been reported in FAP. Increased epithelial cell proliferation in macroscopically normal colonic mucosa of patients with familial polyposis has been shown in vitro by several authors. ${ }^{34-37}$ Deschner and Raicht have also reported crypt epithelial hyperplasia in non-adenomatous colonic mucosa in one patient with FAP ${ }^{38}$ The proliferative stimulus is unknown, but a similar process in the duodenum may be responsible for the hyperplastic changes seen. The finding of Paneth cell hyperplasia, albeit in a small number of patients, is of potential interest. Epidermal growth factor (EGF) is a polypeptide that stimulates cellular growth and differentiation, and in the small intestine is localised in Paneth cells and Brunner's glands. Bulow et al showed numerous EGF immuno- reactive Paneth cells in the duodenal adenomas of two patients with FAP, which were located not as usual in the bottom of the crypts, but all along the crypts, singly or in clusters. ${ }^{39}$ On the basis of these findings a possible role for EGF in the development of duodenal adenomas has been suggested. The clinical importance of duodenal epithelial hyperplasia, so frequently observed in this study, is, as yet, unclear, but we feel it may represent a precursor to neoplastic change.

The prevalance of duodenal adenomas in this series $(92 \%)$ is higher than that of a number of previous reports. ${ }^{7-10}$ Possible factors contributing to this difference are the use of a side viewing video endoscope, allowing better visualisation of the ampulla, and the taking of multiple random biopsy specimens in patients with a macroscopically normal duodenum. The distribution of adenomas in this series, predominantly in the second and third parts of the duodenum with periampullary clustering, has been reported by others ${ }^{40-42}$ and seems to parallel mucosal exposure to bile. A tumour promoting factor in bile, or mucosal hypersensitivity to it have been postulated to explain this observation. ${ }^{2843}$ An observed two-fold increase in prevalence of adenoma at the ampulla compared with the periampullary region ${ }^{13}$ supports this hypothesis, although at present no definitive evidence exists.

There is growing evidence to suggest that the adenoma-carcinoma sequence occurs in the upper gastrointestinal tract in patients with and without polyposis, just as it is known to occur in the colorectum. ${ }^{44-47}$ Patients with FAP who exhibit a high prevalence of duodenal adenomas have a lifetime risk of periampullary carcinoma which has been estimated to be $200-300$ times greater than that of the general population. ${ }^{14}$ Until now, however, it has not been known which patients are at greatest risk of developing malignant change. The severity of duodenal polyposis has been classified on a five grade scale (stages O-IV) based on polyp number, size, histology, and degree of dysplasia. ${ }^{13}$ This provides a quantitative basis for assessing the risk of development of carcinoma. In the study by Spigelman et al 11 patients $(11 \%)$ had stage IV disease ${ }^{13}$; these patients are assumed to be at greatest risk of malignant change and require close endoscopic surveillance. Long term follow up studies are necessary to determine whether this assumption is correct.

We thank Dr B C Morson for his enthusiasm and encouragement and Dr MP Deahl for invaluable help in the preparation of the manuscript.

1 Bodmer WF, Bailey CJ, Bodmer J, et al. Localization of the gene for familial adenomatous polyposis on chromosome . Nature 1987;328:614-6.

2 Hauser G. Uber Polyposis intestinalis adenomatosa und deren Beziehungen zur Krebsentwicklung. Arch Klin Med 1895;55:429-48.

3 Watanabe H, Enjoji M, Yao T, Ohsato K. Gastric lesions in familial adenomatosis coli. Their incidence and histologic analysis. Hum Pathol 1978;9:269-83.

4 Watanabe H, Enjoji M, Yao T, Iida M, Ohsato K. Accompanying gastroenteric lesions in familial adenomatosis coli. Acta Pathol Japan 1977;27:823-39.

5 Utsonomyia J, Maki T, Iwama T, et al. Gastric lesion of familial polyposis coli. Cancer 1974;34:745-54. 
6 Ohsato K, Itoh H, Ikeda S, et al. Follow up study on uppe gastrointestinal lesions in familial polyposis of the colon. Jpn J Gastroenterol 1974;72:141-8.

7 Sarre RG, Frost AG, Jagelman DG, Petras RE, Sivak MV McGannon E. Gastric and duodenal polyps in familial adenomatous polyposis: a prospective study of the nature and prevalence of upper gastrointestinal polyps. Gut and prevalence

8 Ranzi T, Castagnone D, Velio P, Bianchi P, Polli EE. Gastric and duodenal polyps in familial polyposis coli. Gut 1981 22:363-7.

9 Jarvinen HJ, Nyberg M, Peltokallio P. Upper gastrointestinal tract polyps in familial adenomatosis coli. Gut 1983 24:333-9.

10 Jarvinen HJ, Sipponen P. Gastroduodenal polyps in familia adenomatous and juvenile polyposis. Endoscopy 1986;18: $230-4$.

11 Kurtz RC, Sternberg SS, Miller HH, Decosse JJ. Upper gastrointestinal neoplasia in familial polyposis. $D$ ig $D i s ~ S c i$ 1987;32:459-65.

12 Ranzi T, Campanini MC, Velio P, Bianchi PA. Longterm follow-up of upper gastrointestinal tract polyps in 15 patients with familial adenomatous polyposis

13 Spigelman AD, Williams CB, Talbot IC, Domizio P Phillips RKS. Upper gastrointestinal cancer in patients with familial adenomatous polyposis. Lancet 1989;ii: 783-5.

14 Jagelman DG, Decosse JJ, Bussey HJR. Upper gastrointestinal cancer in familial adenomatous polyposis. Lancet 1988;i:1149-51.

15 Spigelman AD, Phillips RKS. Polyposis follow-up and management of the rectum. Ann R Coll Surg Engl 1989; 71:269.

16 Eidt S, Stolte $M$. Gastric glandular cysts-Investigations into their genesis and relationship to colorectal epithelia umours. Z Gastroenterol 1989;27.212-7.

17 Nishiura $M$, Hirota $T$, Itabashi $M$, Ushio K, Yamada $T$ Oguro $Y$. A clinical and histopathological study of gastric polyps in familial polyposis coli. Am J Gastroenterol 1984;79:98-103.

18 Deppisch IM, Rona VT. Gastric epithelial polyps. A 10-year study. J Clin Gastroenterol 1989;11:110-5.

19 Iida $M$, Yao T, Watanabe H, Itoh $H$, Iwashita $A$. Fundic gland polyposis in patients without familial adenomatosis coli: Its incidence and clinical features. Gastroenterol 1984;86: 1437-42.

20 Choi HY, Cooper HS, Sorokin JJ, Gordon SJ. Fundic gland polyposis: Is it a specific lesion related to familial polyposis of the colon? Lab Invest 1984;50:10A.

21 Sipponen P, Siurala M. Cystic "hamartomatous" epithelial polyps of the stomach. Hepatogastroenterology 1978;25: 380-3.

22 Iida $\mathrm{M}$, Yao $\mathrm{T}$, Itoh $\mathrm{H}$, et al. Natural history of gastric adenomas in patients with familial adenomatosis coli/ Gardner's syndrome. Cancer 1988;61:605-11.

23 Murphy ES, Mireless MV, Beltran AO. Familial polyposis of the colon and gastric carcinoma. Concurrent conditions in a 16 year old boy. $J A M A 1962 ; 179: 1026-8$.

24 Goodman AJ, Dundas SAC, Scholefield JH, Johnson BF. Gastric carcinoma and familial adenomatous polyposis Gastric carcinoma and familial ade
(FAP). Int J Color Dis 1988;3:201-3.

25 Iida $M$, Yao $\mathrm{T}$, Itoh $\mathrm{H}$, et al. Natural history of fundic gland polyposis in patients with familial adenomatosis coli/Gardner's syndrome. Gastroenterol 1985;89:1021-5.

26 Lee RG, Burt RW. The histopathology of fundic gland polyps of the stomach. Am J Clin Pathol 1986;86:498-503.
27 Hattori T. Morphological range of hyperplastic polyps and carcinomas arising in hyperplastic polyps of the stomach. $J$ Clin Pathol 1985;38:622-30.

28 Spigelman AD, Williams CB, Grenowska M, Phillips RKS Gastro-duodenal adenomas in polyposis-Is bile the missing link? Gut 1989;30:A710-11.

29 Sipponen P, Laxen F, Seppala K. Cystic "hamartomatous" gastric polyps: a disorder of oxyntic glands. Histopathol 1983;7:729-37.

30 Tatsuta M, Okuda S, Tamura H, Taniguchi H. Gastric hamartomatous polyps in the absence of familial polyposis coli. Cancer 1980;45:818-23.

31 Rohner HG. Drusenkorperzysten des Magens-Erscheinun gsbild und mogiche Entstehungsmechanismen. Leber Magen Darm 1977;7:62-4.

32 Harju E. Gastric polyposis and malignancy. Br J Surg 1986 73:532-3.

33 Ohsato $\mathrm{K}$, Watanabe $\mathrm{H}$, Itoh $\mathrm{H}$, Yao $\mathrm{T}$, Nishimura $\mathrm{M}$ Simultaneous occurrence of multiple gastric carcinomas and familial polyposis of the colon. Jpn J Surg 1974;4: $165-74$

34 Lipkin M. Colonic cell proliferation in familial polyposis. Semin Surg Oncol 1987;3:165-70.

35 Bleiberg H, Mainguet P, Galand P. Cell renewal in familia polyposis. Comparison between polyps and adjacen healthy mucosa. Gastroenterol 1972;63:240-5.

36 Deschner EE, Lipkin $M$. Study of human rectal epithelial cells in vitro. III. RNA, protein, and DNA synthesis in polyps and adjacent mucosa. JNCI 1970;44:175-85.

37 Lipkin M. Phase 1 and phase 2 proliferative lesions of colonic epithelial cells in diseases leading to colon cancer. Cancer 1974; (suppl) 43:878-88.

38 Deschner EE, Raicht RF. Kinetic and morphologic alterations in the colon of a patient with multiple polyposis. Cancer 1981;47:2440-5.

39 Bulow S, Skov Olsen P, Poulsen SS, Kirkegaard P. Is epidermal growth factor involved in the development of duodenal polyps in familial polyposis coli? $\mathrm{Am} \mathrm{J} \mathrm{Gastro-}$ enterol 1988;83:404-6.

40 Alexander JR, Andrews JM, Buchi KN, Lee RG, Becker JM, Burt RW. High prevalence of adenomatous polyps of the duodenal papilla in familial adenomatous polyposis. Dig Dis Sci 1989;34:167-70.

41 Shemesh E, Bat L. A prospective evaluation of the uppe gastrointestinal tract and periampullary region in patients with Gardner's syndrome. Am J Gastroenterol 1985; 80:825-7.

42 Van Stolk R, Sivak MV, Petrini JL, Petras R, Ferguson DR Jagelman D. Endoscopic management of upper gastrointestinal polyps and periampullary lesions in familia adenomatous polyposis and Gardner's syndrome. Endoscopy 1987;19:19-22.

43 Sachatello CR. Familial polyposis of the colon. A fourdecade follow up. Cancer 1971;28:581-7.

44 Perzin KH, Bridge MF. Adenomas of the small intestine: A clinicopathologic review of 51 cases and a study of their relationship to carcinoma. Cancer 1981;48:799-819.

45 Talbot IC, Neoptolemos JP, Shaw DE, Carr-Locke D. Histopathol 1988;12:155-65.

46 Yamaguchi K, Enjoji M. Carcinoma of the ampulla of Vater. A clinicopathologic study and pathological staging of 109 cases of carcinoma and 5 cases of adenoma. Cancer 1987;59:506-15.

47 Sugihara $K$, Muto T, Kamyia J, Konishi F, Sawada T, Morioka Y. Gardner's syndrome associated with periampullary carcinoma, duodenal and gastric adenomatosis. Dis Colon Rectum 1982;25:766-71. 